\title{
Screening for older inpatients at risk for long length of stay: which clinical tool to use?
}

\author{
Olivier Beauchet ${ }^{1,2,3,4^{*}}$ (D), Shek Fung ${ }^{5}$, Cyrille P. Launay ${ }^{6}$, Liam Anders Cooper-Brown ${ }^{3}$, Jonathan Afilalo ${ }^{7}$,
} Paul Herbert ${ }^{8}$, Marc Afilalo ${ }^{9}$ and Julia Chabot $^{1,5}$

\begin{abstract}
Background: Screening for inpatients at risk for long length of stay (LOS) is the first step of an effective hospital care plan for older inpatients. This study aims, in older adults admitted to a geriatric acute care ward, to examine and compare the 6-item brief geriatric assessment (BGA) and the "Programme de Recherche sur l'Intégration des Services pour le Maintien de l'Autonomie" (PRISMA-7) risk levels with long LOS, and to establish their performance criteria (i.e., sensitivity, specificity, positive predictive value, negative predictive value, likelihood ratios) for LOS.

Methods: Based on an observational, retrospective, cohort design, 166 inpatients aged $\geq 75$ admitted to a geriatric acute care ward of a McGill University-affiliated hospital (Montreal, Quebec, Canada) were recruited. The risk levels of the 6-item BGA (low, moderate and high) and the PRISMA-7 (low versus high) were calculated from a baseline assessment. The LOS was subsequently calculated in number of days.

Results: Only the 6-item BGA high risk level was associated with a long LOS (Odds ratio $=1.1$ with $P=0.028$ and Hazard ratio $=2.1$ with $P=0.004$ ). Kaplan-Meier distributions showed that there was no significant difference in the delay of hospital discharge between the low and high-risk level reported by the PRISMA-7 $(P=0.381)$, whereas the 6-item BGA three risk levels differed significantly $(P=0.008)$, with individuals at high risk levels being discharged later when compared to those with low $(P=0.001)$ and moderate $(P=0.019)$ risk levels. Both tools' performance criteria were poor (i.e., < 0.70 ), except for PRISMA-7's sensitivity which was 100\%.

Conclusion: The 6-item BGA risk levels were associated with LOS, low risk-level being associated with short LOS and high-risk level with long LOS, but no association was reported with the PRISMA-7 risk levels. Both tools had poor performance criteria for long LOS, suggesting that they cannot be used as prognostic tools with current scientific knowledge.
\end{abstract}

Keywords: Older inpatients, Epidemiology, Screening, Frailty

\section{Background}

Older (over the age of 65) inpatients are major users of hospital-based acute care services and are a growing group among patients admitted to acute care wards [1-4]. Most of them are admitted to acute care

\footnotetext{
* Correspondence: olivier.beauchet@mcgill.ca

'Department of Medicine, Division of Geriatric Medicine, Sir Mortimer B. Davis - Jewish General Hospital and Lady Davis Institute for Medical Research, McGill University, 3755 chemin de la Côte-Sainte-Catherine, Montréal, QC H3T 1E2, Canada

${ }^{2}$ Dr. Joseph Kaufmann Chair in Geriatric Medicine, Faculty of Medicine, McGill University, Montreal, Quebec, Canada

Full list of author information is available at the end of the article
}

after an Emergency Department (ED) visit [1, 2]. Instead of one straightforward acute disease, older patients present a complex combination of multiple comorbid conditions, which greatly influences their care plans $[3,4]$. For instance, although older inpatients undergo more diagnostic tests and procedures than younger inpatients, their diagnoses tend to be less accurate, slowing down the care plan's design [3-6]. Comorbid conditions may also decompensate in cascade and lead to disabilities, increasing an inpatient's length of stay (LOS) $[5,6]$. Consequently, the LOS of older inpatients is longer than younger inpatients', contributing - against the backdrop of

(c) The Author(s). 2019 Open Access This article is distributed under the terms of the Creative Commons Attribution 4.0 International License (http://creativecommons.org/licenses/by/4.0/), which permits unrestricted use, distribution, and reproduction in any medium, provided you give appropriate credit to the original author(s) and the source, provide a link to the Creative Commons license, and indicate if changes were made. The Creative Commons Public Domain Dedication waiver (http://creativecommons.org/publicdomain/zero/1.0/) applies to the data made available in this article, unless otherwise stated. 
a reduction in the number of hospital beds - to hospital overcrowding [3]. Reduction of LOS is, therefore, one of the main challenges that hospitals face today.

Developing rapid screening methods to estimate the risk of long LOS in older inpatients is relevant, as these can lead to simple and protective subsequent interventions $[3,5,7,8]$. Screening older inpatients with a high risk for long LOS upon ED visits or admissions to acute care wards is, thus, the first step of a hospital care plan that is effective in this population $[3,7,8]$. Several clinical tools have been proposed, but most of them screen for frail conditions or frailty-related issues and adverse events after hospital discharge [9]. Few tools have been designed to screen for the risk of adverse events upon hospital admission and in acute care wards [9]. The only prognostic tool for long LOS is the 6-item brief geriatric assessment (BGA) [7-20]. The 6-item BGA provides a three risk levels for LOS (i.e., low, moderate and high) $[7,8,19]$. The 6-item BGA meets most of the requirements (i.e., fast, easy to use, standardized and based on clinical information collected early in the care process) for being an effective screen of short-term hospital adverse outcomes like long LOS $[16,19,21]$. In Quebec, the "Programme de Recherche sur l'Intégration des Services pour le Maintien de l'Autonomie" (PRISMA-7) is the Ministry of Health and Social Services' reference tool for use in EDs and in acute care wards $[14,15]$. This tool, which stratifies older patients into two disability risk levels (i.e., low versus high), has never had its predictive value of long LOS risk validated. Thus, examining the association between the risk levels reported by the PRISMA-7 and long LOS and comparing them with how the 6-item BGA risk levels are associated with long LOS could be helpful to choose the correct prognosis tool to use. We hypothesized that the 6-item BGA would be better than the PRISMA-7 at predicting long LOS, as it has been designed solely to predict this adverse hospital outcome in acute care wards. This study aims to examine and compare the respective associations of risk levels generated by the 6-item BGA and by the PRISMA-7 with LOS and evaluate both tools' performance criteria (i.e., sensitivity, specificity, positive predictive value $[\mathrm{PPV}]$, negative predictive value $[\mathrm{NPV}]$, likelihood ratios [LR]) for LOS in older adults admitted to a geriatric acute care ward.

\section{Methods}

\section{Participants}

Older inpatients consecutively admitted to a geriatric acute care ward in a university-affiliated hospital were enrolled in this observational retrospective cohort study. The recruited participants were a subgroup of participants enrolled in a previous study [22]. The aim of this first study was to examine whether the 6-item BGA levels of risk for long LOS successfully predicted long LOS in Quebecois geriatric inpatients admitted to a geriatric acute care ward. The period of recruitment was October 2014 to May 2016. The inclusion criteria were: 1) having received both 6-item BGA and PRISMA-7 scores, 2) admission to a geriatric acute care ward after an ED visit and 3) LOS $\leq 2$ months. This threshold of 2 months was established because geriatric acute care wards are designed to take care of acute inpatients and there is no reference average LOS in Quebec's wards. Additionally, inpatients with a LOS above 2 months are administratively reclassified as inpatients in stable medical condition who are waiting for placement in either residences or long-term care facilities. A total of 166 (33.3\%) out of the initial cohort's 499 participants were identified based on selection criteria and selected for this study. Assuming a power of $90 \%$ and a two-sided alpha of 0.5 , the power analysis showed that 150 individuals needed to be recruited to achieve the objective of this second study.

\section{Assessment}

The answers to the 6-item BGA and PRISMA-7 items were collected from patients' medical charts. Both tools' items were completed by nurses upon participant admission to the acute care ward during a short clinical assessment that included a face-to-face interview with patients. Regardless of the tool used, items were answered using a closed-ended format (i.e., yes or no). Based on the answers, points were assigned to each item and a score was calculated.

The items of the BGA are as follows: age $\geq 85$; male; polypharmacy, defined as $\geq 5$ different medications taken daily; presence of home support provided by a health care or social professional, and/or family and/or friend; history of falls in the past 6 months; and temporal disorientation, defined as an inability to give the current month and/or year. 5 points were assigned to history of falls and temporal disorientation and 1 point was assigned to the four other items, as per the results of our previous studies [22]. The score ranged from 0 (lowest risk) to 14 (highest risk) and enabled stratification of the risk for long LOS into three levels: low (score 0 to 3 ), moderate (score 4 to 5 ) and high (score $\geq 6$ ). The other tool, PRISMA-7, is composed of 7 questions, which are as follows: 1) Are you more than 85 years old?; 2) Are you male?; 3) In general, do you have any health problems that require you to limit your activities?; 4) Do you need someone to help you on a regular basis?; 5) In general, do you have any health problems that require you to stay at home?; 6) In case of need, can you count on someone close to you?; and 7) Do you regularly use a stick, walker, or wheelchair to move about? The scoring method used by the PRISMA-7 is to assign 
1 point to the answer yes and no points to the answer no. It stratifies inpatients into two disability risk groups: low (score 0 to 2 ) and high (score 3 to 7 ) risk. Physicians and patients were kept blind to the scores and associated risk levels derived from the 6-item BGA and the PRISMA-7. Reasons for admission were classified into four main categories, which were mobility disorders (i.e., gait and/or balance disorders and/or fall), neuropsychiatric disorders (i.e., delirium, dementia or behavioral disorders), organ failure (i.e., acute organ decompensation) and social issues (i.e., absence of acute diseases accompanied by an inability to cope with increased formal and/or informal home and social support).

\section{Outcomes}

LOS was calculated from the hospital's administrative registry. It was defined as the delay (in days) between the first day of admission to the geriatric acute care ward to the day of discharge from the hospital. A long LOS was defined as one that is in the highest tertile of LOSs (i.e., > 13 days).

\section{Standard protocol approvals, registrations, and participant consent}

Verbal informed consent was obtained from all participants by a systematic and standardized process used in the geriatric acute care ward where the study was performed. Participants or their legal guardians, when appropriate, were informed that their medical information may be used for research purposes. If they disagreed, they informed the physician taking care of them and a note was recorded in their chart. The ethics committee approved this process. No refusal was recorded for this study. The ethics committee of St. Mary's Hospital (Montreal, Quebec, Canada) approved this study.

\section{Statistical analysis}

Means and standard deviations (SD) or frequencies were used to summarize the participants' baseline characteristics. Between-group comparisons were performed using an analysis of variance (ANOVA) with Bonferroni corrections for multiple comparisons, unpaired t-tests or Chi-square tests, as appropriate. Multiple linear, logistic and Cox regression models were used to study the association of LOS (dependent variable) with the risk levels (independent variable) derived from either the 6-item BGA (i.e., low, moderate, high) or the PRISMA-7 (i.e., low versus high). The low risk level was used as a reference level and an adjustment for reasons for admission was performed in all models. The elapsed time between admission to and discharge from the geriatric acute care ward was also examined for the different risk groups (low versus high for PRISMA-7 and low, moderate or high for 6-item BGA) by survival Kaplan-Meier curves and log-rank tests.
The considered performance criteria were sensitivity, specificity, PPV, NPV and LR. P-values $<0.05$ were considered statistically significant. All statistics were performed using SPSS (version 23.0; SPSS, Inc., Chicago, IL).

\section{Results}

Table 1 shows participants' baseline characteristics and comparisons between the groups established via the PRISMA-7 and the 6-item BGA risk levels. The PRISMA-7's high-risk group had higher frequencies of home support $(P \leq 0.001)$ and polypharmacy $(P=0.002)$ than its low-risk group. The 6-item BGA's moderate-risk group was older $(P=0.004)$ and had a higher prevalence of temporal disorientation $(P=0.016)$ and history of falls $(P \leq 0.001)$ than its low-risk group. The prevalence of temporal disorientation $(P \leq 0.001)$ and histories of falls $(P \leq 0.001)$ as well the mean LOS $(P=0.001)$ were higher in the high-risk group when compared to the low-risk group. In addition, there were more males $(P=0.002)$, more temporal disorientation $(P \leq 0.001)$ and higher mean $\operatorname{LOS}(P=0.013)$ in the high-risk group compared to moderate-risk group. There was no significant difference in the other evaluated characteristics.

Only the 6-item BGA risk levels were significantly associated with LOS in linear regressions (Table 2). The low risk level was associated with a short LOS (coefficient of regression $\beta=-4.9$ with $P=0.030$ ) and the high risk level was associated with a long LOS (coefficient of regression $\beta=9.9$ with $P=0.001)$. Multiple logistic and Cox regressions showed that only the 6-item BGA high risk level was associated with a long LOS (Odds ratio $=1.1$ with $P=0.028$ and Hazard ratio $=2.1$ with $P=0.004)$. When it comes to the PRISMA-7 risk levels, Kaplan-Meier distributions showed no significant differences in the time elapsed before hospital discharge between low- and highrisk groups $(P=0.381)$. In contrast, the three participant risk groups established with the 6-item BGA differed significantly when it comes to $\operatorname{LOS}(P=0.008)$, with those in the high-risk group being discharged later than those in the low-risk $(P=0.001)$ and moderate-risk $(P=0.019)$ groups (Fig. 1). All performance criteria were poor (i.e., $<0.70$ ), except the sensitivity of PRISMA-7, which was 1 (Table 3).

\section{Discussion}

The findings show that the 6-item BGA risk levels were associated with LOS, with the low-risk level associated with short LOS and the high-risk level associated with long LOS, but no significant association was reported when using the PRISMA-7 risk levels. In addition, performance criteria were poor for both tools.

The association of the 6-item BGA risk levels with LOS has previously been demonstrated [19, 20]. However, this association was reported in a French older patient cohort $[16,19,21]$. To date, only one study 
Table 1 Baseline characteristics and comparisons between groups of participants categorized with the risk-level stratification of the PRISMA-7 (i.e. low versus high) and the 6-item BGA (i.e. low, moderate and high) $(n=166)$

\begin{tabular}{|c|c|c|c|c|c|c|c|c|c|c|c|}
\hline \multirow[t]{2}{*}{ Baseline Characteristics } & \multirow{2}{*}{$\begin{array}{l}\text { Total } \\
\text { population } \\
(n=166)\end{array}$} & \multicolumn{2}{|c|}{ PRISMA-7 score } & \multirow{2}{*}{$\begin{array}{l}P_{-} \\
\text {Value }^{+}\end{array}$} & \multicolumn{3}{|c|}{ 6-item BGA risk levels } & \multicolumn{4}{|l|}{$P$-Value } \\
\hline & & $\begin{array}{l}\text { Normal } \\
(n=22)\end{array}$ & $\begin{array}{l}\text { Abnormal* } \\
(n=144)\end{array}$ & & $\begin{array}{l}\text { Low } \\
(n=58)\end{array}$ & $\begin{array}{l}\text { Moderate } \\
(n=85)\end{array}$ & $\begin{array}{l}\text { High } \\
(n=23)\end{array}$ & Overall & $\begin{array}{l}\text { Low versus } \\
\text { moderate risk }\end{array}$ & $\begin{array}{l}\text { Low versus } \\
\text { high risk }\end{array}$ & $\begin{array}{l}\text { Moderate } \\
\text { versus } \\
\text { high risk }\end{array}$ \\
\hline Age $\geq 85$ years, $n(\%)$ & $105(63.3)$ & $11(50.0)$ & $94(65.3)$ & 0.166 & $45(77.6)$ & $46(54.1)$ & $14(60.9)$ & 0.016 & 0.004 & 0.127 & 0.563 \\
\hline Male, n (\%) & $41(24.7)$ & $2(9.1)$ & $39(27.1)$ & 0.068 & $16(27.6)$ & $14(16.5)$ & $11(47.8)$ & 0.007 & 0.109 & 0.081 & 0.002 \\
\hline Home support"l, (\%) & $133(80.1)$ & $10(45.5)$ & $123(85.4)$ & $\leq 0.001$ & $47(81.0)$ & $64(75.3)$ & $22(95.7)$ & 0.093 & - & - & - \\
\hline Polypharmacy", n (\%) & $137(82.5)$ & $13(59.1)$ & $124(86.1)$ & 0.002 & $46(79.3)$ & $72(84.7)$ & $19(82.6)$ & 0.706 & - & - & - \\
\hline $\begin{array}{l}\text { Temporal disorientation }{ }^{\S} \text {, } \\
\text { n (\%) }\end{array}$ & $26(15.7)$ & $3(13.6)$ & $23(16.0)$ & 0.779 & $0(0.0)$ & $8(9.4)$ & $18(78.3)$ & $\leq 0.001$ & 0.016 & $\leq 0.001$ & $\leq 0.001$ \\
\hline History of falls", n (\%) & $100(60.2)$ & $11(50.0)$ & $89(61.8)$ & 0.292 & $0(0.0)$ & 77 (90.6) & $23(100.0)$ & $\leq 0.001$ & $\leq 0.001$ & $\leq 0.001$ & 0.126 \\
\hline \multicolumn{12}{|l|}{ Reason for admission, n (\%) } \\
\hline Mobility disorders** & $107(64.5)$ & $13(59.1)$ & $94(65.3)$ & 0.298 & $37(63.8)$ & $57(67.1)$ & $13(56.5)$ & 0.371 & - & - & - \\
\hline $\begin{array}{l}\text { Neuropsychiatric } \\
\text { disorders }^{+\dagger}\end{array}$ & $25(15.1)$ & $4(18.2)$ & $21(14.6)$ & & $8(13.8)$ & $14(16.5)$ & $3(13.0)$ & & - & - & - \\
\hline Organ failure|||| & $15(9.0)$ & $4(18.2)$ & $11(7.6)$ & & $3(5.2)$ & $8(9.4)$ & $4(17.4)$ & & - & - & - \\
\hline Social issue ${ }^{9 !}$ & $19(11.4)$ & $1(4.5)$ & $18(12.5)$ & & $10(17.2)$ & $6(7.1)$ & $3(13.0)$ & & - & - & - \\
\hline \multicolumn{12}{|l|}{ Length of stay ${ }^{\S \S}$ (days) } \\
\hline Mean \pm SD & $14.1 \pm 13.8$ & $11.2 \pm 12.6$ & $14.5 \pm 14.0$ & 0.298 & $11.1 \pm 9.9$ & $13.8 \pm 14.0$ & $22.9 \pm 18.2$ & 0.002 & 0.707 & 0.001 & 0.013 \\
\hline$>13^{\# \#}, \mathrm{n}(\%)$ & $56(33.7)$ & $4(18.2)$ & $52(36.1)$ & 0.98 & $15(25.9)$ & $29(34.1)$ & $12(52.2)$ & 0.078 & - & - & - \\
\hline
\end{tabular}

PRISMA-7: the seven questions "Program of Research on the Integration of Services for the Maintenance of Autonomy"

$B G A$ Brief geriatric assessment

$S D$ standard deviation

*Score $\geq 3 / 7$

${ }^{\dagger}$ Comparison based on unpaired $t$-test or Chi-square test, as appropriate

${ }^{\ddagger}$ Comparison based on ANVOA with Bonferroni correction for multiple comparisons or Chi-square test, as appropriate

"Use of formal (i.e., health and/or social professional) and/or informal (i.e., family and/or friends) home services

"Number of therapeutic classes taken daily $\geq 5$

s Inability to give the month and/or year

\#in the previous 12-month period

**Defined as gait and/or balance disorders and/or fall defined as unintentionally coming to rest on the ground, floor, or other lower level

${ }^{+\dagger}$ Defined as delirium, dementia or behavioral disorders

IIIIDefined as an acute organ decompensation

"I9 Defined as the absence of acute disease symptoms combined with an acute increase of the use of formal and/or informal home and social services,

leading to an inability to stay at their place of residence for life

${ }^{\S}$ Based on the hospital's administrative registry. Corresponds to the delay in days between the first day of admission to geriatric ward and the last day

of hospitalization in the same geriatric ward

\#\#Corresponding to the highest tertile among lengths of stay

$P$-value significant (i.e.; $<0.05$ ) indicated in bold

performed in Quebec showed an association between BGA risk levels and LOS, with high risk levels being associated with long LOS [22]. The 6-item BGA is a prognostic tool for screening short-term frailty-related adverse events. Frailty may be defined as an inability to respond appropriately to stressors like an admission to hospital and is caused by the reduction in physiological resources due to the combined actions of aging and morbidities $[4,5,23,24]$. Thus, frail inpatients require more time to re-attain their baseline conditions, which explains their increased risk of long LOS relative to non-frail inpatients $[5,19,20]$. Given this context, the early detection of possibly frailer inpatients who are at risk for long LOS becomes a cornerstone of older inpatient care. Substantial resources are devoted to reducing the duration and severity of acute diseases in acute wards, but multi-morbidities and disabilities are more likely to be ignored [3]. This last point explains why older inpatients require more staff time and resources than younger inpatients $[1-3,5]$ and, thus, are more prone to short-term adverse outcomes like long LOS. This short-term adverse outcome is one of the major challenges in the demand for hospital services and calls for new care strategies that maintain an effective and efficient hospital care system. Hospital health professionals who take care of older patients are concerned with being able to identify the right patients (i.e., those most at risk of adverse outcomes) at the right time (i.e., as soon as possible) and to introduce the right intervention (i.e., appropriate to the patients' health and functional conditions) with the goal of reducing the occurrence of short-term adverse outcomes [3]. The best way to prevent/reduce adverse outcomes in hospital is to 
Table 2 Multiple regressions showing the association of length of stay in days (dependant variable) with the PRISMA-7 high risk level and the 6-item BGA risk levels (i.e., low, moderate and high) (independent variable, separated model for the PRISMA-7 and the 6 -item brief geriatric assessment) adjusted with reasons for admission $(n=166)$

\begin{tabular}{|c|c|c|c|c|c|c|c|c|c|}
\hline & \multicolumn{3}{|c|}{ Linear regression* } & \multicolumn{3}{|c|}{ Logistic regression $^{\dagger}$} & \multicolumn{3}{|c|}{ Cox regression* } \\
\hline & B & {$[95 \% \mathrm{Cl}]$} & $P$-value & OR & {$[95 \% \mathrm{Cl}]$} & $P$-value & $\mathrm{HR}$ & {$[95 \% \mathrm{Cl}]$} & $P$-value \\
\hline PRISMA-7 Abnormal score & 3.3 & {$[-2.9 ; 9.6]$} & 0.295 & 2.6 & {$[0.8 ; 7.9]$} & 0.107 & 1.2 & {$[0.8 ; 1.9]$} & 0.398 \\
\hline \multicolumn{10}{|c|}{ A priori 6-item BGA levels of risk } \\
\hline Low & -4.9 & {$[-9.3 ;-0.5]$} & 0.030 & Ref. & & & Ref. & & \\
\hline Moderate & -0.3 & {$[-4.6 ; 4.0]$} & 0.887 & 0.4 & {$[0.7 ; 3.2]$} & 0.279 & 1.3 & {$[0.9 ; 1.8]$} & 0.195 \\
\hline High & 9.9 & {$[4.0 ; 15.9]$} & 0.001 & 1.1 & {$[1.1 ; 8.5]$} & 0.028 & 2.1 & {$[1.3 ; 3.4]$} & 0.004 \\
\hline
\end{tabular}

PRISMA-7: the seven questions "Program of Research on the Integration of Services for the Maintenance of Autonomy"

$B G A$ Brief geriatric assessment

$B$ Coefficient of regression beta

OR Odds ratio

HR Hazard ratio

Cl Confidence interval

Ref Referent condition

*Length of stay used as a continuous dependant variable

'Length of stay used as a discontinuous variable defined as the highest tertile of lengths of stay (i.e., $>13$ days)

All models adjusted with reason for admission, including mobility disorders (i.e., gait and/or balance disorders and/or fall, defined as unintentionally coming to rest on the ground, floor, or other lower level), neuropsychiatric disorders (i.e., delirium, dementia or behavioral disorders), organ failure (i.e., acute organ decompensation) or social issue (i.e., absence of symptoms of acute diseases combined with an acute increase of the use of formal and/or informal home and social services, leading to an inability to stay at their place of residence for life)

Coefficient of regression beta, odds ratio, hazard ratio and $P$-value significant (i.e.; $<0.05$ ) indicated in bold

screen those older patients at the highest risk as soon as possible (i.e., earlier in the care plan) such that they receive timely and appropriate interventions $[1,2]$.

The predictive tools designed for this purpose should provide a relevant stratification of risk and information for the hospital care plan early $[1,2]$. The use of clinical information has been shown to be the better strategy in the development of predictive tools when compared to administrative data collection $[1,2,6,10-12]$. As such, this approach has generated several screening tools which: 1) use the same categories of variables, including demographic, social, physical and functional parameters; 2) are based on information collected via questions asked to patients and/or their relatives, instead of recorded via physical examination; 3) provide a score based on an accumulation of points wherein all items have the same value; 4) and provide two levels of risk: low versus high [7-20]. Among these screening tools, most like ISAR and TRST have been developed for EDs [8-13]. In Quebec, the PRISMA-7 is the reference tool provided by the Ministry of Health and Social Services of Quebec $[14,15]$. However, this tool has only been validated to screen for disabilities and only in older community dwellers whose medical conditions are stable $[14,15]$. The PRISMA-7 is not easy to implement in hospitals because its questions do not always lead to objective answers, particularly when it comes to acute conditions. Indeed, it requires collecting information on the patient's history by asking questions to the patients themselves or to their relatives. This can sometimes lead to subjective/inaccurate answers that do not reflect the patient's real status. In addition, due to the increased prevalence of cognitive impairment among older users of acute care wards, obtaining reliable information is all the more difficult [6-10]. Another weakness of the PRISMA-7 is that it only predicts medium-term agerelated adverse outcomes like disability, whereas inhospital professionals need relevant information about short-term adverse outcomes [3]. No association between the PRISMA-7 high risk level and LOS has been reported in our results, suggesting that the PRISMA-7 is not an appropriate tool to screen age-related short-term adverse events in older inpatients admitted to acute care wards.

Both the 6-item BGA and the PRISMA-7 have a limited number of items that are not specific to older inpatients. In addition, we showed that their performance criteria were poor, suggesting that they cannot be used as prognosis tool for long LOS with current scientific knowledge. Taking into consideration the reasons for admission or increasing the number of items could improve the predictive value of these clinical tools. We examined this hypothesis for the 6-item BGA in a previous study [20]. We suggest that increasing the number of items found on the BGA from 6 to 10 could improve its accuracy and performance criteria for predicting long LOS. We demonstrated that the performance criteria of the 10-item BGA for the prediction of long LOS were higher than the 6-item BGA [20]. We also highlighted that chronic conditions were the main contributors to a good predictive value. However, a tool's usability is important to take into consideration. Increasing the number of items tends to decrease tools' usability. The 

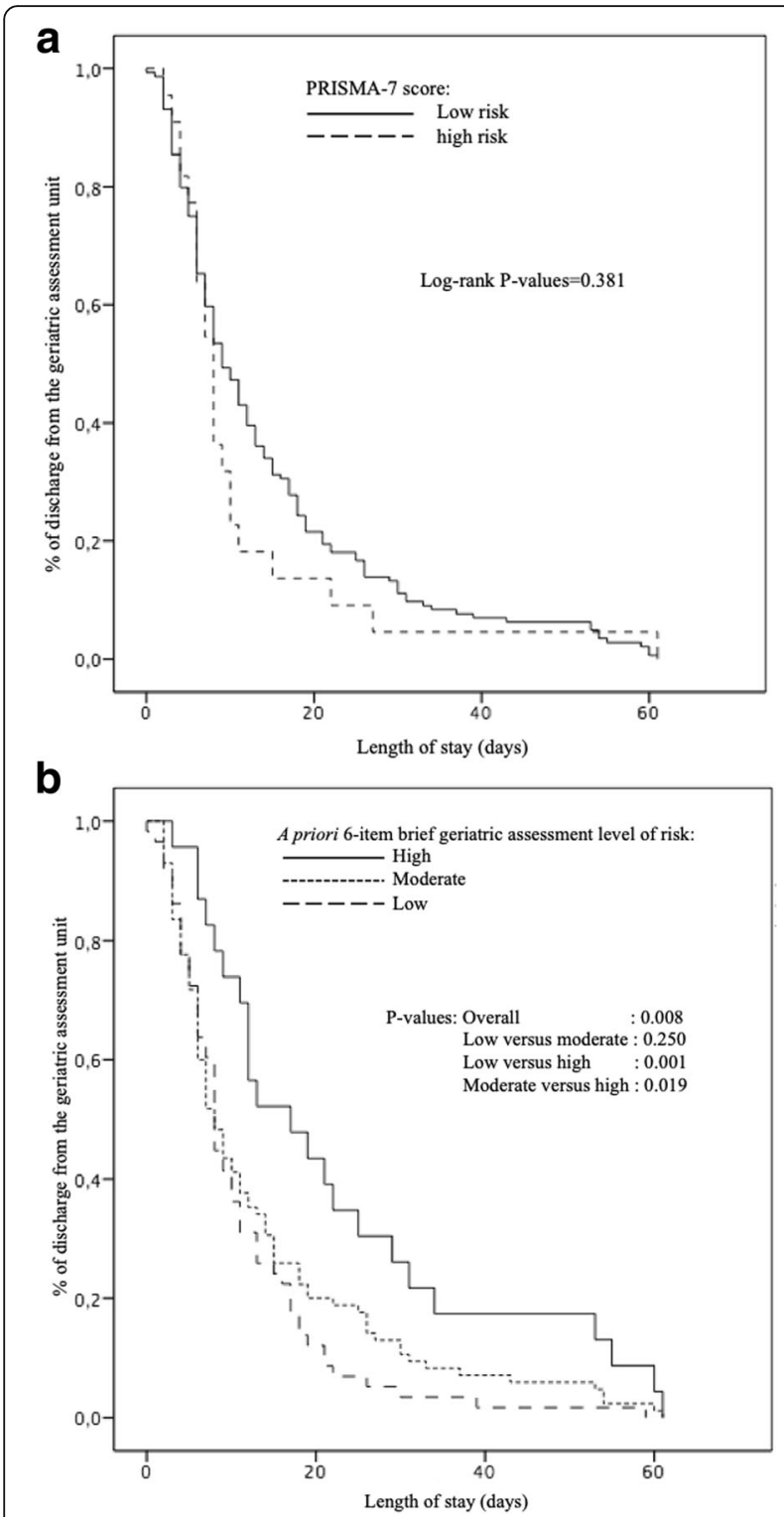

Fig. 1 Kaplan-Meier estimates of the probability of discharge from the geriatric acute care ward based on PRISMA-7 risk levels (i.e.; low versus high) (a) and on the 6-item BGA risk levels (i.e.; low, moderate, high) $(\mathbf{b})(n=166)$. PRISMA-7: the seven questions "Program of Research on the Integration of Services for the Maintenance of Autonomy". BGA: Brief geriatric assessment

choice of including only 6 items in the BGA has been made in order to take into account "real-life" conditions of practice. In fact, it has been shown that screening tools must be completable in less than 5 min to be considered usable in daily practice [25].

There are limitations to our study. First, the recruitment of participants was performed in a single centre and the number of participants recruited was a small sample. Thus, the studied cohort is not representative of inpatients admitted to acute care wards at the
Table 3 Performance criteria of risk levels of the 6-item brief geriatric assessment and the PRISMA-7 for long lengths of hospital stay* $(n=166)$

\begin{tabular}{|c|c|c|c|}
\hline \multirow[t]{2}{*}{ Performance criteria } & \multicolumn{2}{|c|}{$\begin{array}{l}\text { 6-item brief geriatric } \\
\text { assessment risk level }\end{array}$} & \multirow{2}{*}{$\begin{array}{l}\text { Abnormal } \\
\text { PRISMA-7 } \\
\text { score }^{+}\end{array}$} \\
\hline & Moderate & High & \\
\hline Sensitivity & 0.56 & 0.23 & 1.00 \\
\hline Specificity & 0.08 & 0.14 & 0.03 \\
\hline Positive predictive value & 0.34 & 0.52 & 0.36 \\
\hline Negative predictive value & 0.67 & 0.69 & 0.82 \\
\hline Likelihood ratio of positive test & 0.60 & 0.27 & 1.03 \\
\hline Likelihood ratio of negative test & 0.17 & 0.18 & - \\
\hline
\end{tabular}

PRISMA-7: the seven questions "Program of Research on the Integration of Services for the Maintenance of Autonomy"

*Length of stay used as a discontinuous variable defined as the highest tertile of lengths of stay (i.e., $>13$ days)

${ }^{+}$Score $\geq 3 / 7$

population level, which limits the results' external validity. Second, the retrospective collection of data from patient medical charts limited what information was collected. It could be suggested that other, non-collected variables may influence the relationship between the 6item BGA and the PRISMA-7's risk levels and LOS. Third, a potential recall bias may affect the reported history of falls. Indeed, falls are more frequently underreported in older adults than in younger adults, because memory impairment can lead this population to forget the occurrence of falls [26].

\section{Conclusions}

The 6-item BGA risk levels was associated with LOS in older inpatients admitted to acute care wards, with older adults classified as high-risk having a greater risk of long LOS when compared to the two other risk levels. In contrast, the PRISMA-7 failed to identify those older inpatients who underwent long LOS. However, both tools had poor performance criteria for long LOS, suggesting that they cannot be used as prognostic tools with current scientific knowledge.

Further research is needed to confirm this first result.

\section{Abbreviations}

ANOVA: Analysis of variance; BGA: Brief geriatric assessment; ED: Emergency Department; LOS: Length of stay; PRISMA-7: "Programme de Recherche sur I'Intégration des Services pour le Maintien de I'Autonomie"; SD: Standard deviation

\section{Acknowledgements}

The authors are grateful to the participants for their participation.

\section{Authors' contributions}

JC: Data collection, statistical analysis, interpretation of data, drafting and revising manuscript for important intellectual content. OB: Study conception, statistical analysis, interpretation of data, drafting and revising manuscript. SF: participant recruitment, interpretation of data, revising manuscript. CPL: interpretation of data, drafting and revising manuscript. JA: interpretation of 
data and revising manuscript. $\mathrm{PH}$ : interpretation of data and revising manuscript. LACB and MA: revising manuscript. All authors approved and read the final manuscript.

\section{Funding}

Not applicable

\section{Availability of data and materials}

The datasets used and analyzed in the current study will be made available by the corresponding author upon reasonable request.

\section{Ethics approval and consent to participate}

The study was conducted in accordance with the ethical standards set forth in the Helsinki Declaration (1983). All patients admitted to the geriatric acute care ward of the university-affiliated hospital or their legal guardian, when appropriate, were informed that their medical information could be used for research purposes. The obtained informed consent was verbal. The ethics committee approved this informed consent, as it is generically obtained for all patients admitted to the geriatric ward of St. Mary's hospital and because data collection was retrospective. In case of refusal, patients informed the physician in charge of the geriatric acute care ward verbally and this information was noted in their medical chart. There was no refusal to use medical information for research purposes in the participants recruited for this study. The ethics committee of St. Mary's Hospital (Montreal, Quebec, Canada) approved the study.

\section{Consent for publication}

Prior to analysis, all participant-identifying information was removed.

\section{Competing interests}

The authors declare that they have no competing interests.

\section{Author details}

'Department of Medicine, Division of Geriatric Medicine, Sir Mortimer B. Davis - Jewish General Hospital and Lady Davis Institute for Medical Research, McGill University, 3755 chemin de la Côte-Sainte-Catherine, Montréal, QC H3T 1E2, Canada. ${ }^{2}$ Dr. Joseph Kaufmann Chair in Geriatric Medicine, Faculty of Medicine, McGill University, Montreal, Quebec, Canada. ${ }^{3}$ Centre of Excellence on longevity of McGill integrated University Health Network, Montreal, Quebec, Canada. ${ }^{4}$ Lee Kong Chian School of Medicine, Nanyang Technological University, Singapore, Singapore. ${ }^{5}$ Department of Medicine, Division of Geriatric Medicine, St. Mary's Hospital Center, McGill University, Montreal, Quebec, Canada. ${ }^{6}$ Geriatric Medicine and Geriatric Rehabilitation ServiceDepartment of Medicine, Lausanne University Hospital, Lausanne, Switzerland. ${ }^{7}$ Division of Cardiology and Centre for Clinical Epidemiology, Jewish General Hospital and McGill University, Montreal, Quebec, Canada. ${ }^{8}$ Department of medicine, Montreal university Hospital and University of Montreal, Montreal, Quebec, Canada. ${ }^{9}$ Emergency Department, Jewish General Hospital, McGill University, Montreal, QC, Canada.

Received: 9 October 2018 Accepted: 21 May 2019

Published online: 06 June 2019

\section{References}

1. Ellis G, Gardner M, Tsiachristas A, Langhorne P, Burke O, Harwood RH, Conroy SP, Kircher T, Somme D, Saltvedt I, Wald H, O'Neill D, Robinson D, Shepperd S. Comprehensive geriatric assessment for older adults admitted to hospital. Cochrane Database Syst Rev. 2017;9:CD006211.

2. Ellis G, Whitehead MA, Robinson D, O'Neill D, Langhorne P. Comprehensive geriatric assessment for older adults admitted to hospital: meta-analysis of randomised controlled trials. BMJ. 2011;343:d6553.

3. Kellett J. Hospital Medicine (Part 1): what is wrong with acute hospital care? Eur J Intern Med. 2009;20:462-4.

4. Lang PO, Heitz D, Hedelin G, Dramé M, Jovenin N, Ankri J, Somme D, Novella JL, Gauvain JB, Couturier P, Voisin T, De Wazière B, Gonthier R, Jeandel C, Jolly D, Saint Jean O, Blanchard F. Early markers of prolonged hospital stays in older people: a prospective, multicenter study of 908 inpatients in French acute hospitals. J Am Geriatr Soc. 2006;547:1031-9.

5. Gill TM, Gahbauer EA, Han L, Allore HG. Trajectories of disability in the last year of life. N Engl J Med. 2010;362:1173-80.
6. Wolff JL, Starfield B, Anderson G. Prevalence, expenditures, and complications of multiple chronic conditions in the elderly. Arch Intern Med. 2002;162:2269-76.

7. Beauchet O, Launay C, de Decker L, Fantino B, Kabeshova A, Annweiler C. Who is at risk of long hospital stay among patients admitted to geriatric acute care unit? Results from a prospective cohort study. J Nutr Health Aging. 2013;17:695-9.

8. Beauchet $\mathrm{O}$, Launay CP, Fantino B, Lerolle N, Maunoury F, Annweiler C. Screening for elderly patients admitted to the emergency department requiring specialized geriatric care. J Emerg Med. 2013;4:739-45.

9. Preston L, Chambers D, Campbell F, Cantrell A, Turner J, Goyder E. What evidence is there for the identification and management of frail older people in the emergency department? A systematic mapping review. Southampton (UK): NIHR Journals Library. 2018. Pubmed ref: PMID 29697231.

10. Salvi F, Morichi V, Grilli A, Giorgi R, De Tommaso G, Dessi-Fulgheri P. The elderly in the emergency department: a critical review of problems and solutions. Intern Emerg Med. 2007;2(4):292-301.

11. McCusker J, Bellavance F, Cardin S, Trépanier S, Verdon J, Ardman O. Detection of older people at increased risk of adverse health outcomes after an emergency visit: the ISAR screening tool. J Am Geriatr Soc. 1999;47:1229-37.

12. Mion LC, Palmer RM, Anetzberger GJ, Meldon SW. Establishing a casefinding and referral system for at-risk older individuals in the emergency department setting: the SIGNET model. J Am Geriatr Soc. 2001;49:1379-86.

13. Moons P, De Ridder K, Geyskens K, Sabbe M, Braes T, Flamaing J, Milisen K. Screening for risk of readmission of patients aged 65 years and above after discharge from the emergency department: predictive value of four instruments. Eur J Emerg Med. 2007;14:315-23.

14. Hébert R, Raîche M, Dubois MF, Gueye NR, Dubuc N, Tousignant M, PRISMA Group. Impact of PRISMA, a coordination-type integrated service delivery system for frail older people in Quebec (Canada): A quasi-experimental study. J Gerontol B Psychol Sci Soc Sci. 2010;65B:107-18.

15. Raîche M, Hébert R, Dubois MF. PRISMA-7: a case-finding tool to identify older adults with moderate to severe disabilities. Arch Gerontol Geriatr. 2008;47:9-18.

16. Kansagara D, Englander H, Salanitro A, Kagen D, Theobald C, Freeman M, Kripalani S. Risk prediction models for hospital readmission: a systematic review. JAMA. 2011;306:1688-98.

17. Launay $C$, de Decker L, Hureaux-Huynh R, Annweiler C, Beauchet O. Mobile geriatric team and length of hospital stay among older inpatients: a casecontrol pilot study. J Am Geriatr Soc. 2012;60:1593-4.

18. Launay CP, Annweiler C, de Decker L, Kabeshova A, Fantino B, Beauchet O Risk of in-hospital mortality following emergency department admission: results from the geriatric EDEN cohort study. J Nutr Health Aging. 2014;18:83-6.

19. Launay CP, de Decker L, Kabeshova A, Annweiler C, Beauchet O. Screening for older emergency department inpatients at risk of prolonged hospital stay: the brief geriatric assessment tool. PLoS One. 2014;9:e110135.

20. Launay CP, Rivière $H$, Kabeshova $A$, Beauchet $O$. Predicting prolonged length of hospital stay in older emergency department users: use of a novel analysis method, the Artificial Neural Network. Eur J Intern Med. 2015;26:478-82.

21. Karam G, Radden Z, Berall LE, Cheng C, Gruneir A. Efficacy of emergency department-based interventions designed to reduce repeat visits and other adverse outcomes for older patients after discharge: A systematic review. Geriatr Gerontol Int. 2015;15:1107-017.

22. Beauchet O, Fung S, Launay CP, Afilalo J, Herbert P, Afilalo M, Chabot J. Predicting a long hospital stay after admission to a geriatric assessment unit: Results from an observational retrospective cohort study. Maturitas. 2018;115:110-4.

23. Berrut G, Andrieu S, Araujo de Carvalho I, Baeyens JP, Bergman H, Cassim B, Cerreta F, Cesari M, Cha HB, Chen LK, Cherubini A, Chou MY, Cruz-Jentoft AJ, De Decker L, Du P, Forette B, Forette F, Franco A, Guimaraes R, GuttierrezRobledo LM, Jauregui J, Khavinson V, Lee WJ, Peng LN, Perret-Guillaume C, Petrovic M, Retornaz F, Rockwood K, Rodriguez-Manas L, Sieber C, Spatharakis G, Theou O, Topinkova E, Vellas B, Benetos A. Promoting access to innovation for frail old persons. IAGG (International Association of Gerontology and Geriatrics), WHO (World Health Organization) and SFGG (Société Française de Gériatrie et de Gérontologie) Workshop--Athens January 20-21, 2012 Tool (GFST). J Nutr Health Aging. 2013;17:688-93.

24. Rockwood K, Bergman H. FRAILTY: A Report from the 3(rd) Joint Workshop of IAGG/WHO/SFGG, Athens, January 2012. Can Geriatr J. 2012;15:31-6. 
25. Elliott A, Hull L, Conroy SP. Frailty identification in the emergency department-a systematic review focussing on feasibility. Age Ageing. 2017;46:509-13.

26. Cummings SR, Nevitt MC, Kidd S. Forgetting falls. The limited accuracy of recall of falls in the elderly. J Am Geriatr Soc. 1988;367:613-6.

\section{Publisher's Note}

Springer Nature remains neutral with regard to jurisdictional claims in published maps and institutional affiliations.

Ready to submit your research? Choose BMC and benefit from:

- fast, convenient online submission

- thorough peer review by experienced researchers in your field

- rapid publication on acceptance

- support for research data, including large and complex data types

- gold Open Access which fosters wider collaboration and increased citations

- maximum visibility for your research: over $100 \mathrm{M}$ website views per year

At $B M C$, research is always in progress.

Learn more biomedcentral.com/submissions 